\title{
Classification and clinical evaluation of the types of angiokeratoma
}

\section{Khalifa Sharquie ${ }^{1}$, Raed I Jabbar ${ }^{2}$}

\author{
${ }^{1}$ Department of Dermatology, College of Medicine, University of Baghdad, Medical City Teaching Hospital, Baghdad, Iraq. \\ ${ }^{2}$ Department of Dermatology, Falluja Teaching Hospital, Al-Anbar Health Directorate, Anbar, Iraq
}

Corresponding author: Prof. Khalifa Sharquie, E-mail: ksharquie@ymail.com

\begin{abstract}
Background: Angiokeratoma is a group of benign vascular telangiectasias in the superficial dermis associated with hyperkeratosis of the epidermis. There are different types of angiokeratoma and the color of the lesions-pink, red, dusky red, blue-red_-depends on their age. Materials and Methods: Twenty-four patients with different varieties of angiokeratoma were collected from April 2013 through March 2020 and classified according to well-defined types. Each patient gave their formal consent after the nature of the disease was explained to them. Full medical history taking and clinical examination were performed on all patients. Skin biopsies were taken from 12 cases and processed for histopathology with H\&E stain. As for therapy, diathermy was used for the treatment of selected localized cases, especially those on the scrotum. Results: Twenty-four cases with different types of angiokeratoma were evaluated, 19 (79.16\%) males and 5 (20.83\%) females, with ages ranging from 13 to 25 years and a mean age of 19 years. The age of onset was most commonly around adolescence and early adulthood. The lesions were classified into the following: 11 (45.83\%) cases of Fordyce, 5 (20.83\%) cases solitary, 4 (16.66\%) cases circumscriptum, 3 (12.5\%) cases oral (on the tongue), and one (4.16\%) corporis diffusum (Fabry disease). All patients displayed warty red, blue, or black papules, nodules, or plaques, with the exception of isolated angiokeratoma. Their histopathology revealed hyperkeratosis of the epidermis, which could have been mild or marked acanthosis, as seen in the form of pseudoepithelial hyperplasia with marked elongation of rete ridges. As a dermal change, markedly dilated blood vessels occupied the papillary and reticular dermis. Diathermy was an effective mode of therapy in selected patients with satisfactory cosmetic and therapeutic results. Conclusion: All types of angiokeratoma were recognized but the most common were angiokeratoma of Fordyce, mainly affecting male genitalia, followed by solitary angiokeratoma, affecting mainly the limbs, and angiokeratoma circumscriptum linearly along the limbs. Oral angiokeratoma of the tongue appeared in three patients. All these types have a characteristic presentation that is easy to recognize: warty dusky-red lesions.
\end{abstract}

Key words: Angiokeratoma; Classification; Papules; Histopathology

\section{INTRODUCTION}

Angiokeratomas are well-circumscribed vascular lesions characterized by superficial vascular ectasia and hyperkeratosis [1]. Five variants of angiokeratoma have to date been recognized.

1. Solitary or multiple angiokeratomas. This is the most common type and one that is frequent in males [2]. They are small, warty, black papules 2-10 $\mathrm{mm}$ in diameter on the lower limbs, but may be seen anywhere on the body. Trauma or chronic irritation of the walls of vessels in the superficial dermis can lead to the formation of new angiokeratomas [1].

2. Angiokeratoma of Fordyce. This type is located on the scrotum or vulva and is the second most common type of angiokeratoma [2]. Its prevalence in the general population is around $0.16 \%[3,4]$, accounting for $14 \%$ of all angiokeratomas [3]. As the age increases, its prevalence increases from $0.6 \%$ of males aged 16 years to $16.7 \%$ of males aged 70 years or above [5].

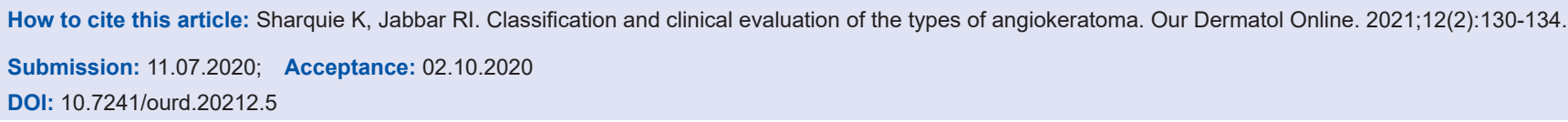


Clinically, angiokeratoma of Fordyce appears as multiple well-circumscribed and dome-shaped papules, 2-5 mm in diameter, predominantly on the scrotum. In rare cases, the lesions may be located on the shaft of the penis, glans penis, inguinal areas, buttocks, abdomen, upper thighs in males, and vulva in females [5-7]. The lesions are red, blue, purple, or bluish-black [8]. In rare cases, they may be correlated with thrombophlebitis, inguinal hernias, or varicoceles. Vulvar lesions may be observed with vulvar varicosities, hemorrhoids, oral contraception, or elevated venous pressure during pregnancy [1].

3. Angiokeratoma corporis diffusum. This type is characterized by the evolution of numerous lesions, commonly in a bathing-trunk distribution, varying in number, and appearing mostly during late childhood and adolescence. X-linked recessive Fabry disease is the best-known entity with this clinical feature, which results from an insufficiency of the enzyme $\alpha$-galactosidase A [1].

4. Angiokeratoma of Mibelli: This type is characterized by lesions appearing mainly between the ages of 10 and 15 years, most commonly located on the dorsal and lateral sides of the fingers and toes. They can appear on the dorsa of the hands and feet and, rarely, on the elbows and knees. Angiokeratoma of Mibelli may be associated with perniosis or acrocyanosis and shows an autosomal dominant inheritance pattern [1].

5. Angiokeratoma circumscriptum. In general, these lesions are solitary, although numerous lesions may appear in adulthood, and are commonly located on the lower limbs. They may appear anywhere on the skin, including the tongue, and may be multiple and disseminated, creating a band-like appearance. They are often asymptomatic but may become a concern if they turn excessively dark or black. The lesions may even be present at birth, since angiokeratoma circumscriptum can either be congenital or acquired. Generally, this type of angiokeratoma more commonly appears in childhood and early adulthood, and is predominant in females [9].

The pathology of angiokeratoma involves the dilation of vessels in the papillary dermis together with epidermal hyperkeratosis, acanthosis, and elongated rete ridges usually encircling dilated vessels $[2,10]$.

\section{Management}

Because most cases are asymptomatic, there is no need for treatment except for cosmetic improvements and in the case of symptomatic lesions. Treatment includes shave excision, cryotherapy, electrocautery, and laser therapy. The choice between these different modalities depends on the size of the lesions [1].

\section{MATERIALS AND METHODS}

This was a descriptive clinical case-series study that collected twenty-four patients with different types of angiokeratoma from April 2013 through March 2020. These cases were classified according to well-defined types. Each patient gave their formal consent after the nature of the disease was explained to them.

A medical history was properly taken in each case, including the sex and age of the patient, the duration and age of onset of the disease, the associated symptoms and skin disorders, and a medical and drug history.

A complete clinical examination was conducted to identify the site, size, and color of each lesion, the associated signs, and the morphological distribution and patterns.

Skin biopsies were taken from 12 cases and processed for histopathology with H\&E stain.

Pathological findings and clinical pictures were matched together for a clinicopathological relationship to classify all variants.

The diagnosis of Fabry disease was based on clinical pictures, laboratory results, and systemic manifestations.

As for therapy, diathermy was used for the treatment of selected localized cases, especially those on the scrotum.

\section{RESULTS}

\section{Clinical Results}

Twenty-four cases with different types of angiokeratoma were evaluated, 19 (79.16\%) males and 5 (20.83\%) females, with ages ranging from 13 to 25 years and a mean age of 19 years. The age of onset was most commonly in adolescence and early adulthood.

The lesions were classified into the following: 11 (45.83\%) cases of Fordyce, 5 (20.83\%) cases solitary, 4 (16.66\%) cases circumscriptum, $3(12.5 \%)$ cases oral (on the tongue), and one (4.16\%) corporis diffusum 
(Fabry disease) (Figs. $1-5)$ (Table 1). No cases of angiokeratoma of Mibelli were seen in our study.

The color of each lesion varied from pink to red to dusky red to blue-red to black depending on its age. Normally, most of the lesions were asymptomatic but occasional bleeding, mild pain, and mild itching were observed. All patients displayed warty red, blue, or black papules, nodules, or plaques.

With the exception of isolated angiokeratoma of the tongue seen in two sisters, no family history of angiokeratoma was recorded with the other types of angiokeratoma.
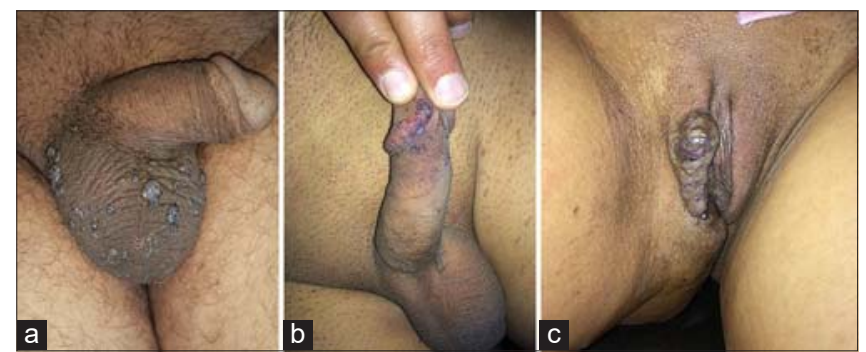

Figure 1: Angiokeratoma of Fordyce involving (a) the scrotum, (b) the shaft and glans penis, and (c) the vulva.

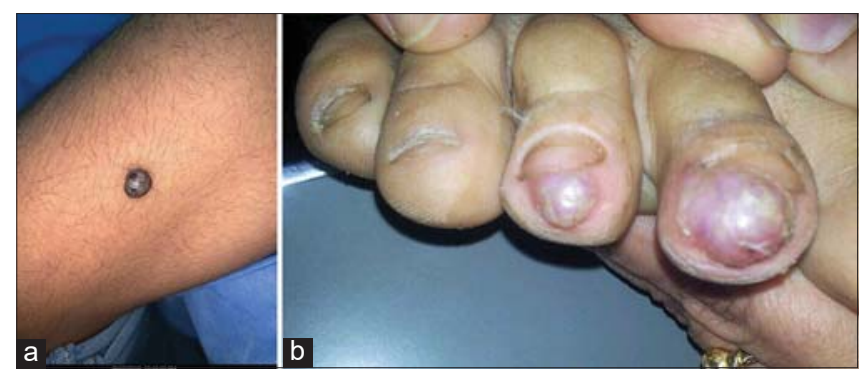

Figure 2: Solitary angiokeratoma affecting (a) the thigh and (b) toes.

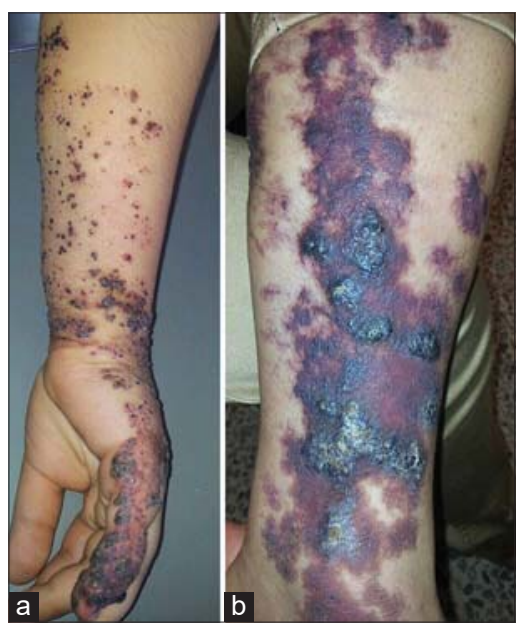

Figure 3: Angiokeratoma circumscriptum affecting (a) the upper limb in a 13-year-old male and (b) the left leg in a 22-year-old female.

\section{Pathological Results}

The epidermis showed hyperkeratosis, which could have been mild or marked acanthosis, as seen in the form of pseudoepithelial hyperplasia with marked elongation of rete ridges (Fig. 6). As a dermal change,

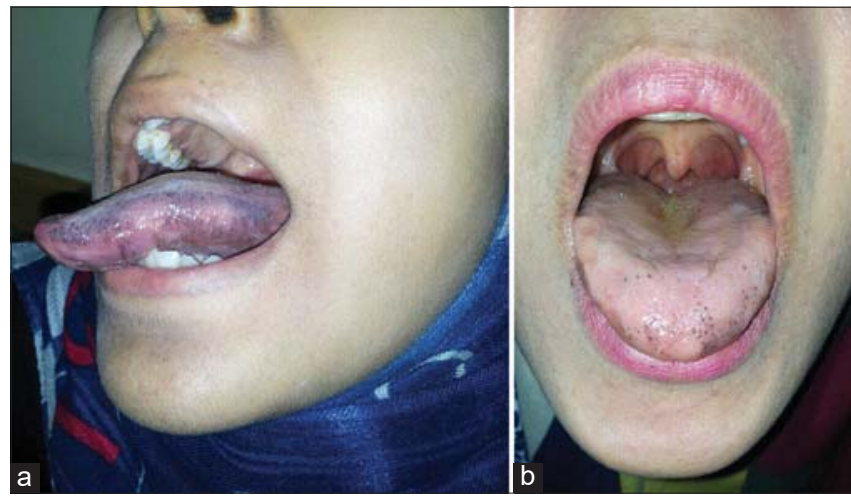

Figure 4: $(a-b)$ Isolated angiokeratoma of the tongue in two adult sisters.

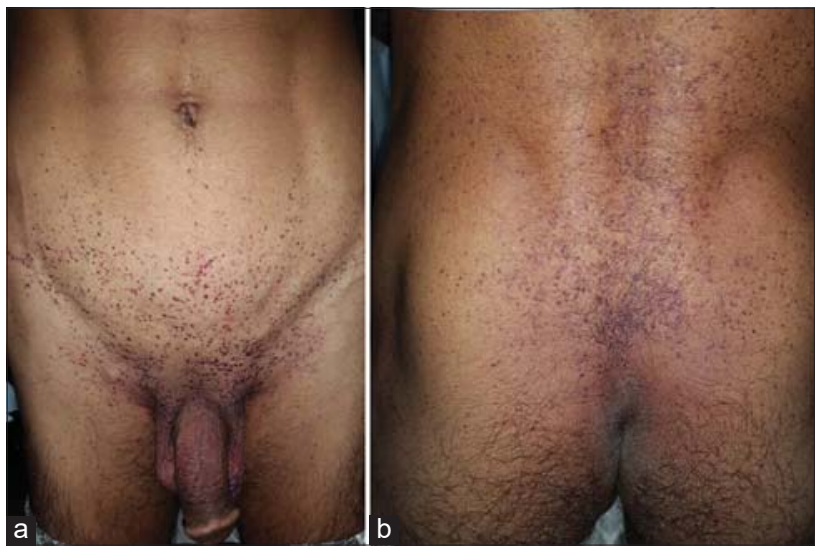

Figure 5: Angiokeratoma corporis diffusum (Fabry disease) in a 24-year-old male affecting (a) the lower abdomen, genital and inguinal regions, and inner thighs and (b) the lower back and gluteal region.

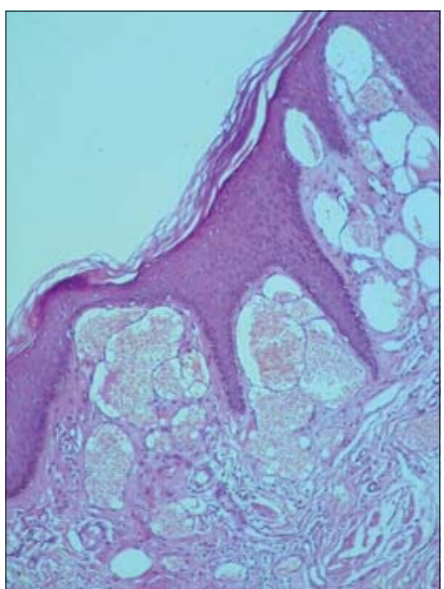

Figure 6: Angiokeratoma with hyperkeratosis, mild acanthosis, and elongated epidermal rete ridges encircling dilated superficial dermal vessels (H\&E, 4x). 
Table 1: Distribution of lesions in relation to type, site, and the sex of the patient

\begin{tabular}{|c|c|c|c|c|}
\hline Type & No. of cases & Sex & Predominant sites & Frequency (\%) \\
\hline Fordyce & 11 & $\begin{array}{l}10 \text { males } \\
1 \text { female }\end{array}$ & $\begin{array}{l}\text { Scrotum and penis in males } \\
\text { Vulva in females }\end{array}$ & 45.83 \\
\hline Solitary & 5 & $\begin{array}{l}4 \text { males } \\
1 \text { female }\end{array}$ & Lower limbs & 20.83 \\
\hline Circumscriptum & 4 & $\begin{array}{l}3 \text { males } \\
1 \text { female }\end{array}$ & $\begin{array}{l}\text { Lower limbs }(n=3) \\
\text { Upper limbs }(n=1)\end{array}$ & 16.66 \\
\hline Isolated of the tongue & 3 & $\begin{array}{l}2 \text { females } \\
1 \text { male }\end{array}$ & Tongue & 12.5 \\
\hline Corporis diffusum & 1 & 1 male & $\begin{array}{l}\text { Lower abdomen } \\
\text { Inguinal region } \\
\text { Scrotum and penis } \\
\text { Upper thigh } \\
\text { Lower back } \\
\text { Gluteal region }\end{array}$ & 4.16 \\
\hline
\end{tabular}

markedly dilated blood vessels occupied the papillary and reticular dermis (Fig. 7). Additionally, some of the vessels were located inside the epidermis.

\section{Treatment}

Diathermy was an effective mode of therapy in selected patients with satisfactory cosmetic and therapeutic results.

\section{DISCUSSION}

To the best of our knowledge, this is the first study of angiokeratoma in Iraq on a significant number of cases in which clinical and histopathological examination and classification of the different types of angiokeratoma were performed.

A clinicopathological study by Imperial et al. showed that, out of 116 cases with different types of angiokeratoma, $82 \%$ of them were males and $18 \%$ were females, while the age of onset was frequently in the second and third decades of life [2].

In our study, the age of onset was most commonly in adolescence and early adulthood; $79.16 \%$ of cases were males and 20,83\% were females. These results are consistent with other studies $[2,11]$.

The clinical features and morphological distribution of the lesions investigated in this study were similar to other publications $[1-4,11]$.

As for the types of angiokeratoma, our study determined that angiokeratoma of Fordyce was the most common type, as seen in $45.83 \%$ of cases, followed by solitary angiokeratoma in $20.83 \%$ of cases. These results are unlike those in some other studies, in which solitary

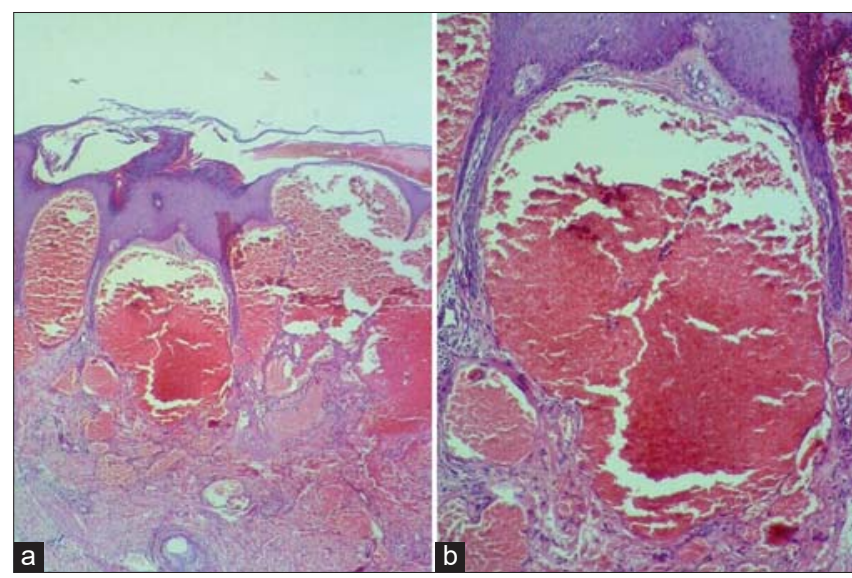

Figure 7: Angiokeratoma with hyperkeratosis, mild acanthosis, and elongated rete ridges in the epidermis with evident dilated blood vessels in the upper dermis (H\&E; a: 4x, b: 10x).

angiokeratoma was the most common, followed by angiokeratoma of Fordyce $[2,11]$.

The variability between the results of our study and other studies is difficult to explain but might be due to racial differences or individual concerns about the health and appearance of the genitalia.

Oral angiokeratoma is usually seen as a component of Fabry disease and is rarely observed with other types of angiokeratoma. Isolated angiokeratoma of the tongue is extremely rare and only 19 cases have been recorded by other studies [12]. In our study, there were 3 cases of isolated angiokeratoma of the tongue, two sister females and one male, and this is, to the best of our knowledge, the first piece of research to record three cases of isolated angiokeratoma of the tongue in one single study.

For reasons unknown to us, angiokeratoma of Mibelli was not seen in our study. 
Most lesions were asymptomatic, but occasional bleeding, mild pain, and mild itching were observed, which aligns with other sources [2].

Histopathological manifestations included hyperkeratosis, mild acanthosis, and pseudoepithelial hyperplasia in the epidermis and dilated blood vessels in the papillary and reticular dermis. These results are similar to the pathologies of angiokeratoma reported by other studies $[2,10]$.

The diagnosis of angiokeratoma should not generally be challenging, as it depends mainly on clinical pictures. However, histopathology might be necessary in some cases to confirm the diagnosis. Because a solitary angiokeratoma may be mistaken as a melanocytic nevus, wart, hemangioma, or even malignant melanoma [2], proper history taking and careful examination and pathological evaluation are highly recommended to reach a correct diagnosis, especially if doubts arise.

The treatment of angiokeratoma is difficult, especially in the case of extensive lesions, but diathermy may be used selectively for localized lesions, as in the scrotum. Pulsed dye laser (PDL), argon laser, neodymium-doped yttrium aluminum garnet (Nd:YAG) laser, and $\mathrm{CO}_{2}$ laser are alternatives forms of treatment [13-15].

\section{CONCLUSION}

Our study observed all types of angiokeratoma but the most common was angiokeratoma of Fordyce, mainly affecting male genitalia and even the vulva in females, followed by solitary angiokeratoma, affecting mainly the limbs, and angiokeratoma circumscriptum linearly along the limbs. Isolated angiokeratoma of the tongue was seen in three patients. All these types have a characteristic presentation that is easy to recognize: warty dusky-red lesions.

\section{Statement of Human and Animal Rights}

All the procedures followed were in accordance with the ethical standards of the responsible committee on human experimentation (institutional and national) and with the 2008 revision of the Declaration of Helsinki of 1975.

\section{Statement of Informed Consent}

Informed consent for participation in this study was obtained from all patients.

\section{REFERENCES}

1. North PE. Vascular neoplasm and neoplastic like proliferation. In: Bolognia JL, Sccaffer JV, Ceroni L. Text book of dermatology, $4^{\text {th }}$ edition. China, Elsevir, 2018;18,114:2020-2040.

2. Imperial R, Helwig EB. Angiokeratoma. A clinicopathological study. Arch Dermatol. 1967;95:166-75.

3. Schiller PI, Itin PH. Angiokeratomas: an update. Dermatology. 1996;193:275-82.

4. Zaballos P, Daufí C, Puig S, Argenziano G, Moreno-Ramírez D, Cabo H, et al. Dermoscopy of solitary angiokeratomas: a morphological study. Arch Dermatol. 2007;143:318-25.

5. Bechara FG, Jansen T, Wilmert M, Altmeyer P, Hoffmann K. Angiokeratoma Fordyce of the glans penis: combined treatment with erbium: YAG and $532 \mathrm{~nm}$ KTP (frequency doubled neodynium: YAG) laser. J Dermatol. 2004;31:943-5.

6. Patrizi A, Neri I, Trevisi P, Landi C, Bardazzi F. Congenital angiokeratoma of Fordyce. J Eur Acad Dermatol Venereol. 1998;10:195-6.

7. Pianezza ML, Singh D, van der Kwast T, Jarvi K. Rare case of recurrent angiokeratoma of Fordyce on penile shaft. Urology. 2006;68:891.e1-3.

8. Erkek E, Basar MM, Bagci Y, Karaduman A, Bilen CY, Gokoz A. Fordyce angiokeratomas as clues to local venous hypertension. Arch Dermatol. 2005;141:1325-6.

9. Goldsmith PC. Dermatosis resulting from disorders of the veins and arteries. In: Griffiths C, Barker J, Bleiker T, Chalmers R, Creamer D. Rook's Textbook of Dermatology, 9th ed. Singapore, Blackwell Science. 2016;87:8-14.

10. Caputo R, Ackermann BA, Sison-Torre EQ: Angiokeratoma; in Caputo R, Ackermann B A: Pediatric Dermatology and Dermatopathology. Philadelphia, Lea and Febiger. 1994 pp 127-137.

11. Naranjo-Sintes R, Pereda-Hernandez J, Delgado-Florencio V, Linares-Solano J. Angioqueratoma: apropisito de 93 observaciones. Med Cutan Ibero Lat Am. 1988;16:255-61.

12. Hamid R, Chalkoo AH, Singh I, Wani S, Bilal S. Isolated angiokeratomas of the tongue: a rare entity. Indian J Dent Res. 2019;30:322-6.

13. Nguyen J, Chapman LW, Korta DZ, Zachary CB. Laser treatment of cutaneous angiokeratomas: a systematic review. Dermatol Ther. 2017;30.

14. Baumgartner J, Šimaljaková M. Genital angiokeratomas of Fordyce 595-nm variable-pulsed pulsed dye laser treatment. J Cosmet Laser Ther. 2017;19:459-64.

15. Burnett CT, Kouba DJ. A rare case of congenital angiokeratoma of the glans penis treated using a 595-nm pulsed dye laser. Dermatol Surg. 2012;38:2028-30.

Copyright by Khalifa Sharquie, et al. This is an open-access article distributed under the terms of the Creative Commons Attribution License, which permits unrestricted use, distribution, and reproduction in any medium, provided the original author and source are credited. Source of Support: Nil, Conflict of Interest: None declared. 